\title{
Pulmonary haemodynamics in obstructive sleep apnoea: time course and associated factors
}

\author{
H. Schäfer*, E. Hasper*, S. Ewig*, U. Koehler**, J. Latzelsberger*, S. Tasci*, B. Lüderitz*
}

Pulmonary haemodynamics in obstructive sleep apnoea: time course and associated factors. H. Schäfer, E. Hasper, S. Ewig, U. Koehler, J. Latzelsberger, S. Tasci, B. Lüderitz. CERS Journals Ltd 1998.

ABSTRACT: Changes in pulmonary artery pressure within an obstructive apnoea and elevations of transmural pulmonary artery pressure $(P$ pa,tm $)$ towards the end of apnoea are well known. The purpose of our study was to examine which factors contribute to the increase of $\boldsymbol{P}$ pa,tm in an apnoea. In addition, the time course of $\boldsymbol{P}$ pa,tm and associated factors during a sleep study was investigated.

We analysed the association of changes in arterial oxygen saturation $\left(S_{\mathrm{a}}, \mathrm{O}_{2}\right)$, oesophageal pressure $(P$ oes $)$ to estimate intrathoracic pressure, systolic blood pressure (BPsys) to estimate left ventricular afterload, apnoea duration and the change in $P_{p a, t m}\left(\Delta P_{\text {pa,tm }}\right)$ during the course of obstructive apnoeas. Consecutive apnoeas in nonrapid eye movement (NREM)-sleep at the beginning, the middle and the end of the sleep study were analysed in six patients with obstructive sleep apnoea.

The mean systolic $P$ pa,tm was $28.0 \pm 12.1 \mathrm{mmHg}$ at the beginning of apnoea and $38.6 \pm 15.5 \mathrm{mmHg}$ at the end $(\Delta P \mathrm{pa}, \mathrm{tm} 10.5 \pm 7.4 \mathrm{mmHg} ; \mathrm{p}<0.0001) . \Delta S_{\mathrm{a}, \mathrm{O}_{2}}(\mathrm{p}<0.0001$; odds ratio $(\mathrm{OR}) 1.45$; confidence interval $(\mathrm{CI})$ 1.20-1.76) and $\triangle P_{\text {oes }}(\mathbf{p}<0.0001$; OR 1.22; CI 1.11-1.34) were independently associated with $\Delta P$ pa,tm in a multiple regression analysis. Apnoea duration as well as $\Delta P$ oes, $\Delta P$ pa,tm and $\Delta S_{\mathrm{a}}, \mathrm{O}_{2}$ were all significantly higher $(\mathbf{p}<0.05)$ in apnoeas at the middle of the sleep study than at the beginning or the end.

In conclusion, hypoxaemia and mechanical factors as an increase in negative thoracic pressure contribute to elevations of the transmural pulmonary artery pressure during an obstructive apnoea. The time course of pulmonary haemodynamics within a steep study reveals that the highest transmural pulmonary artery pressure occurs in the middle of the night with no progressive increase towards the end of the sleep study.

Eur Respir J 1998; 12: 679-684.
*Dept of Internal Medicine, University of Bonn, Bonn, Germany. **Dept of Internal Medicine, Philipps-University Marburg, Marburg, Germany.

Correspondence: H. Schäfer

Medizinische Universitätsklinik und Poliklinik Bonn

Innere Medizin/Kardiologie und Pneumologie

Sigmund-Freud-Str. 25

D-53105 Bonn

Germany

Fax: 492282874707

Keywords: Obstructive sleep apnoea pulmonary artery pressure

pulmonary haemodynamics

Received: January 151998

Accepted after revision 30 March 1998

This study was supported by a grant from the Deutsche Forschungsgemeinschaft (Scha 690/1-1)
Pulmonary hypertension is a potential complication of obstructive sleep apnoea. Most recent studies agree on a $15-20 \%$ prevalence [1]. The development of pulmonary hypertension is strongly linked to an obstructive ventilatory pattern, daytime hypoxaemia and hypercapnia, whereas the severity of obstructive sleep apnoea plays only a minor role [2]. However, some patients develop pulmonary hypertension despite normal waking arterial oxygen tension $\left(\mathrm{Pa}_{\mathrm{a}} \mathrm{O}_{2}\right)$ levels [3]. In this group of patients, the nocturnal breathing disorder may be crucial for the development of pulmonary hypertension, since it has been hypothesized that episodic and recurrent hypertension, due to repeated apnoeas, could lead to permanent pulmonary hypertension [4].

Transient and repetitive elevations in pulmonary artery pressure, with reference to atmospheric pressure, have been described [5]. While intravascular pulmonary artery pressure decreases during apnoea and increases at the resumption of breathing, transmural pulmonary artery pressure $(P \mathrm{pa}, \mathrm{tm})$ (i.e. corrected for intrathoracic pressure swings) shows a trend toward a progressive increase throughout an apnoea and toward a decrease once ventilation has been resumed [6]. Several factors and mechanisms, mainly mechanical events or hypoxic vasoconstriction, have been proposed as contributing to the changes in the pulmonary artery pressure $(P \mathrm{pa}, \mathrm{tm})$ within an apnoea cycle. Mechanical events are caused preferably by intrathoracic pressure swings [7]. Limitation of left ventricular filling and emptying at low intrathoracic pressure could contribute to an increase in pulmonary vascular resistance by increasing the pulmonary venous pressure and blood volume [8]. On the other hand, several studies have indicated an association between changes in oxygen saturation and changes in pulmonary artery pressure during an obstructive apnoea [4, 9, 10]. MARRone et al. [11] showed that hypoxia is a major determinant of the slow changes in the transmural pulmonary artery pressure over the whole course of an apnoea. In addition, they found rapid changes in the $P$ pa,tm that was synchronous with intrathoracic pressure changes breathby-breath.

The purpose of our study was to examine which factors contribute to the increase of the $P$ pa,tm in an apnoea. Is this: 1), a response to increased right ventricular preload 
and output due to increased venous return in the course of intrathoracic pressure swings; 2), due to pulmonary vasoconstriction related to hypoxia; or 3), due to increased left ventricular afterload. Moreover, we analysed the time course of these factors within the sleep study.

\section{Methods}

All patients underwent full diagnostic polysomnographic sleep studies to establish the diagnosis of obstructive sleep apnoea. Conventional spirography and body plethysmography, echocardiography, bicycle exercise test and right heart catheterization were performed on the following day. The following sleep study included the haemodynamic measurements of pulmonary artery pressure and systemic artery pressure. The study was approved by the Ethics Committee of the University of Bonn, Germany. All patients gave written informed consent to all parts of the study.

\section{Patients}

Six male patients with moderate-to-severe obstructive sleep apnoea (apnoea/hypopnoea index (AHI) >20) were included in the study. No patient had a history or clinical signs of chronic airflow limitation. Patients with a history of coronary heart disease were excluded. Echocardiography revealed normal left ventricular diameters and normal ejection fraction in all patients. All antihypertensives and diuretics were discontinued $72 \mathrm{~h}$ before the study.

\section{Pulmonary artery catheterization and blood pressure measurement}

The pulmonary artery catheterization procedure was performed in the heart catheterization laboratory. Patients were at rest in a semirecumbent position, breathing room air. A Swan-Ganz catheter (Corodyn TD-E, B. Braun, Melsungen, Germany) was introduced into the pulmonary artery via a cubital vein and connected to a pressure transducer (Exadyn CMS Transducer, B. Braun). After calibrating the system, measurements of the pressures in the right atrium $(P \mathrm{ra})$ and the right ventricle $(P$ rv $)$ were performed. The correct position of the catheter in the pulmonary artery was verified by chest radiography screening and by the typical wave-form of the pulmonary artery pressure. Recordings of the pulmonary artery pressure $(P$ pa) and the pulmonary capillary wedge pressure $(P \mathrm{pcw})$ were performed at rest and at exercise. Invasive blood pressure measurement was performed by a cannula in the left-sided arteria radialis. After connection to a pressure transducer the system was calibrated. At the end of the protocol in the heart catheterization laboratory the patients were transferred into the sleep laboratory and the sleep study was started within the next $6 \mathrm{~h}$.

\section{Sleep studies}

Polysomnography included the following signals: two leads of electroencephalogram $\left(\mathrm{C}_{4} \mathrm{~A}_{1} ; \mathrm{C}_{3} \mathrm{~A}_{2}\right)$, two leads of electro-oculogram and a submental electromyogram were continuously registered by surface electrodes. Respiration was also continuously recorded: airflow was monitored by oronasal thermistors, abdominal and chest wall movements by inductive-plethysmography, and arterial oxygen saturation $\left(\mathrm{Sa}_{\mathrm{a}} \mathrm{O}_{2}\right)$ by pulse oximetry. Oesophageal pressure $\left(P_{\text {oes }}\right)$, as an estimate of intrathoracic pressure, was recorded by a piezo catheter (Gaeltec CTO, Novotronic GMBH Bonn, Germany) introduced in the lower third of the oesophagus and connected to a pressure transducer (Gaeltec S7b, Novotronic GMBH Bonn, Germany). The procedure of catheter placement was performed as described elsewhere in detail [12]. In addition, $P$ pa and systemic artery blood pressure (BP) were recorded continuously after connection to a pressure transducer and calibration was performed before starting the sleep study as follows: the whole system including the pressure transducer, the pressure monitor (Sirecust 404, Siemens München, Germany) and the computerized recording system (NewMedics Öhringen, Germany) was calibrated by two-point calibration using a mercury manometer for high level pressure and atmosphere for 0 level pressure. The transducer was placed $5 \mathrm{~cm}$ below the sternal angle manubriosternal joint. Systolic $P$ pa,tm was calculated by computerized subtraction of $P$ oes from systolic $P$ pa.

All variables were recorded by a computerized system (NewMedics, Öhringen, Germany). Sleep was staged manually according to standard criteria [13]. Central, obstructive, and mixed apnoeas were defined according to the usual criteria [14]. We defined hypopnoea as a reduction of at least $50 \%$ in airflow from its value during quiet wakefulness for at least $10 \mathrm{~s}$ followed either by an oxygen desaturation of at least $4 \%$ or by an arousal. The total number of apnoea and hypopnoea were divided by total sleep time to make up the apnoea index (AI) and the hypopnoea index (HI). The sum of AI and HI then became the AHI.

\section{Haemodynamic analysis}

In each patient, 15 consecutive obstructive apnoeic cycles in nonrapid eye movement (NREM)-sleep in the first two hours (b), in the following two hours (m) and in the last two hours (e) of the sleep study were selected for analysis. An apnoeic cycle was divided into three phases as shown schematically in figure 1 and included the first three unoccluded breaths following the preceding occluded breaths. In every apnoeic cycle the following variables were calculated: duration of the apnoea, lowest systolic $P$ pa,tm at the beginning of the apnoea $(P$ pa,tm b, phase I), highest systolic $P$ pa,tm at the end of the apnoea or the first three unoccluded breaths following the apnoea $(P \mathrm{pa}, \mathrm{tm} \mathrm{e}$,

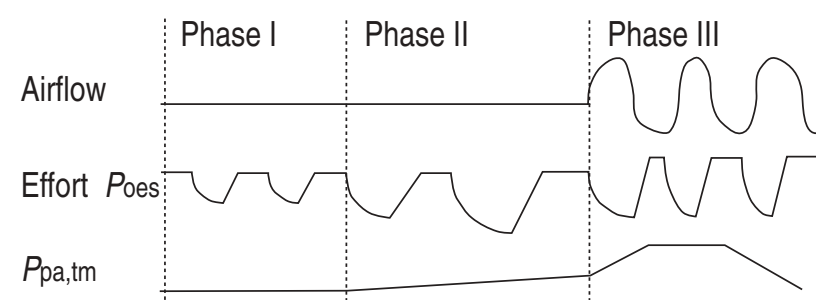

Fig. 1. - Schematic presentation of an obstructive apnoea in three phases. $P_{\text {oes: }}$ oesophageal pressure; $P$ pa,tm: transmural pulmonary artery pressure. 


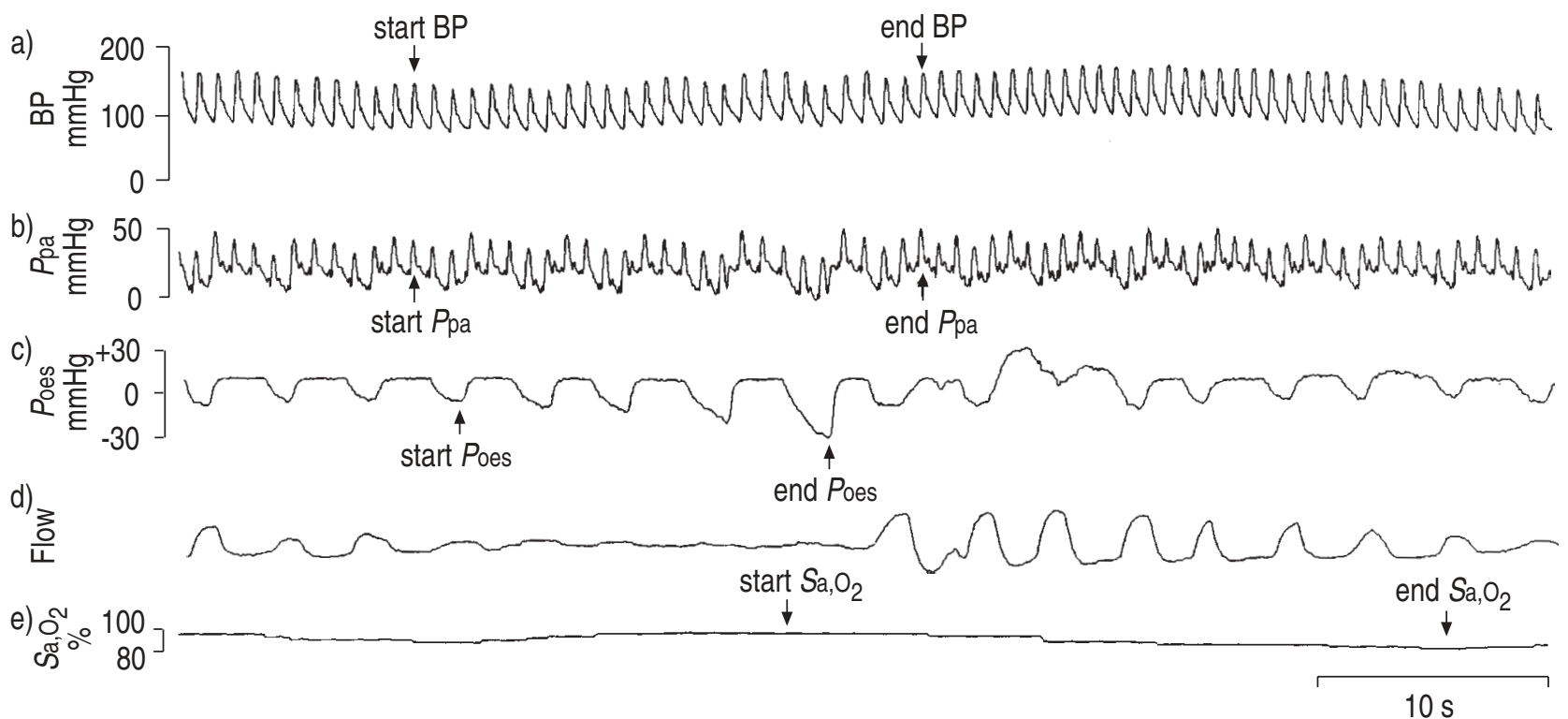

Fig. 2. - Representative traces of the haemodynamic changes during an obstructive apnoea. a) blood pressure (BP); b) pulmonary artery pressure $\left(P\right.$ pa); c) oesophageal pressure $(P$ oes $)$; d) flow; and e) arterial oxygen saturation $\left(\mathrm{Sa}_{2} \mathrm{O}_{2}\right)$. Arrows indicate values taken in phase I (start) and phase II or III (end) of the apnoea. $(1 \mathrm{mmHg}=0.133 \mathrm{kPa}$.)

phase II or phase III). Both values were taken during end expiratory time; the difference between both was given as $\Delta P$ pa,tm. The corresponding systolic BP at the beginning of the apnoea (BPsys b) and at the end of the apnoea or the first three unoccluded breaths following the apnoea (BPsys e) were calculated and the difference between the two made up the $\Delta \mathrm{BP}_{\text {sys. }}$. The highest $P_{\text {oes }}$ at the beginning of the apnoea $\left(P_{\text {oes }} \mathrm{b}\right)$ and the lowest $P_{\text {oes }}$ at the end of the apnoea or the first three unoccluded breaths following the apnoea $\left(P_{\text {oes }}\right.$ e) were calculated and the difference between the two made up the $\Delta P$ oes. The highest $S a, O_{2}$ at the beginning of the apnoea $\left(\mathrm{Sa}_{\mathrm{a}} \mathrm{O}_{2} \mathrm{~b}\right)$ and the lowest $\mathrm{Sa}_{\mathrm{a}} \mathrm{O}_{2}$ at the end of the apnoea $\left(\mathrm{S}_{\mathrm{a}} \mathrm{O}_{2} \mathrm{e}\right)$ were calculated and the difference between both made up the $\Delta \mathrm{Sa}_{\mathrm{a}} \mathrm{O}_{2}$. Figure 2 gives an illustration of a representative tracing.

\section{Statistical analysis}

Descriptive statistics for continuous variables were expressed as the mean \pm standard deviation (SD), unless stated otherwise. We assessed differences in continuous variables using the Mann-Whitney U-test. Analysis of variance (ANOVA) with Bonferroni correction was used to deter- mine differences between the beginning, middle and end of the sleep study with regard to apnoea duration, $\Delta P$ pa,tm $\Delta$ BPsys, $\Delta P$ oes and $\Delta S_{\mathrm{a}}, \mathrm{O}_{2}$. We performed a multiple linear regression analysis to assess factors independently associated with $\Delta P$ pa,tm. In all cases, $p$-values of $<0.05$ were considered to be significant. Statistical analysis was performed with the Statistical Package for the Social Sciences (SPSS) for Windows ${ }^{\mathrm{TM}}$ (SPSS Inc., Chicago, IL, USA).

\section{Results}

The mean age of the six patients was $54.7 \pm 6.5 \mathrm{yrs}$, the mean body-mass index (BMI) was $31.1 \pm 4.1 \mathrm{~kg} \cdot \mathrm{m}^{-2}$. The mean AHI was 52.1 \pm 13.5 (31-67). Detailed data on the patients' characteristics in detail are given in table 1 . Detailed results of the polysomnography are given in table 2 .

We analysed a total of 270 obstructive apnoeas in NREM-sleep from six patients. The mean (range) duration of the 270 apnoeas was $22.7 \pm 12.7 \mathrm{~s}(10.0-94.0 \mathrm{~s})$. Ana-lysis of the pulmonary haemodynamics revealed a mean systolic $P$ pa,tm of $28.0 \pm 12.1 \mathrm{mmHg}$ at the beginning of apnoea and $38.6 \pm 15.5 \mathrm{mmHg}$ at the end of apnoea $(\Delta P$ pa,tm $10.5 \pm 7.4 \mathrm{mmHg} ; \mathrm{p}<0.0001)$. The corresponding

Table 1. - Data on patients' lung function and haemodynamic measures at rest (awake) and on exercise

\begin{tabular}{|c|c|c|c|c|c|c|c|c|c|c|c|c|c|}
\hline $\begin{array}{c}\text { Patient } \\
\text { No. }\end{array}$ & $\begin{array}{l}\text { Age } \\
\text { yrs }\end{array}$ & $\begin{array}{l}\mathrm{BMI} \\
\mathrm{kg} \cdot \mathrm{m}^{2}\end{array}$ & $\begin{array}{l}\text { FEV1 } \\
\% \text { pred }\end{array}$ & $\begin{array}{c}\mathrm{VC} \\
\% \text { pred }\end{array}$ & $\begin{array}{c}P \mathrm{a}, \mathrm{O}_{2} \text { rest } \\
\mathrm{mmHg}\end{array}$ & $\begin{array}{c}P \mathrm{a}, \mathrm{O}_{2} \\
\text { exercise } \\
\mathrm{mmHg}\end{array}$ & $\begin{array}{c}P \mathrm{a}, \mathrm{CO}_{2} \text { rest } \\
\mathrm{mmHg}\end{array}$ & $\begin{array}{c}\mathrm{Pa}_{\mathrm{a}, \mathrm{CO}_{2}} \\
\text { exercise } \\
\mathrm{mmHg}\end{array}$ & $\begin{array}{l}P \text { ra rest } \\
\text { mmHg }\end{array}$ & $\begin{array}{l}P \text { pa rest } \\
\text { mmHg }\end{array}$ & $\begin{array}{c}P \text { pa } \\
\text { exercise } \\
\text { mmHg }\end{array}$ & $\begin{array}{l}P \text { pc rest } \\
\mathrm{mmHg}\end{array}$ & $\begin{array}{c}P \text { pc } \\
\text { exercise } \\
\text { mmHg }\end{array}$ \\
\hline 1 & 64 & 26.5 & 72 & 92 & 68.6 & 85.5 & 43.3 & 33.6 & 7 & 13.0 & 20.0 & 10.0 & 12.0 \\
\hline 2 & 54 & 30.2 & 78 & 77 & 62.8 & 77.6 & 43.3 & 41.4 & 6 & 15.3 & 32.0 & 5 & 9 \\
\hline 3 & 51 & 32.5 & 130 & 109 & 66.6 & 98.3 & 42.3 & 38.5 & 4 & 10.3 & 22.6 & 7 & 19 \\
\hline 4 & 51 & 30.4 & 73 & 70 & 61.4 & 65.0 & 43.7 & 46.3 & 5 & 30.6 & 54.0 & 5 & 10 \\
\hline 5 & 61 & 28.7 & 107 & 87 & 77.9 & 91.0 & 37.3 & 39.0 & 4 & 11.0 & 19.0 & 4 & 6 \\
\hline 6 & 47 & 38.3 & 86 & 72 & 63.1 & 72.0 & 38.6 & 38.5 & 2 & 10.0 & 19.0 & 2 & 17 \\
\hline Iean & 54.7 & 31.1 & 90.5 & 84.6 & 66.7 & 81.6 & 41.5 & 39.1 & 4.7 & 15.0 & 27.8 & 5.5 & 12.1 \\
\hline$\pm \mathrm{SD}$ & \pm 6.5 & \pm 4.1 & \pm 23.7 & \pm 14.6 & \pm 6.1 & \pm 12.4 & \pm 2.8 & \pm 4.5 & \pm 1.8 & \pm 7.9 & \pm 13.8 & \pm 2.7 & \pm 4.9 \\
\hline
\end{tabular}

BMI: body mass index; $\mathrm{FEV}_{1}$ : forced expiratory volume in one second; $\mathrm{VC}$ : vital capacity; $P_{\mathrm{a}, \mathrm{O}_{2}}$ : arterial oxygen tension; $P \mathrm{a}, \mathrm{CO}_{2}$ : arterial $\mathrm{CO}_{2}$ tension; $P$ ra: right atrial pressure; $P$ pa: pulmonary artery pressure; $P$ pc: pulmonary capillary pressure. $(1 \mathrm{mmHg}=0.133 \mathrm{kPa}$.) 
Table 2. - Polysomnographic data

\begin{tabular}{|c|c|c|c|c|c|c|c|c|c|c|c|}
\hline $\begin{array}{l}\text { Patient } \\
\text { No. }\end{array}$ & $\begin{array}{l}\text { TST } \\
\min \end{array}$ & $\begin{array}{c}\text { Stage } 1 \\
\%\end{array}$ & $\begin{array}{c}\text { Stage } 2 \\
\%\end{array}$ & $\begin{array}{c}\text { Stage } 3 \\
\%\end{array}$ & $\begin{array}{c}\text { Stage } 4 \\
\%\end{array}$ & $\begin{array}{c}\text { Stage REM } \\
\%\end{array}$ & $\begin{array}{l}\text { Apnoea } \\
\text { index } \\
\text { events } \cdot h-1\end{array}$ & $\begin{array}{l}\text { Hypopnoea } \\
\text { index } \\
\text { events } \cdot h-1\end{array}$ & $\begin{array}{c}\text { AHI } \\
\text { events } \cdot h^{-1}\end{array}$ & $\begin{array}{c}\text { Mean } \\
\mathrm{Sa}_{\mathrm{a}} \mathrm{O}_{2} \\
\%\end{array}$ & $\begin{array}{c}\text { Minimal } \\
\mathrm{Sa}_{\mathrm{a}} \mathrm{O}_{2} \\
\%\end{array}$ \\
\hline 1 & 335 & 7.8 & 62.0 & 8.4 & 2.3 & 3.6 & 53.3 & 6.7 & 60.0 & 92 & 75 \\
\hline 2 & 326 & 17.0 & 47.0 & 16.0 & 0 & 5.6 & 30.1 & 0.9 & 31.0 & 94 & 79 \\
\hline 3 & 367 & 29.0 & 51.0 & 0 & 0 & 0.9 & 46.1 & 7.6 & 53.7 & 95 & 68 \\
\hline 4 & 340 & 32.0 & 44.0 & 0 & 0 & 2.8 & 52.9 & 14.2 & 67.1 & 89 & 60 \\
\hline 5 & 187 & 29.0 & 20.0 & 0 & 0 & 0 & 59.4 & 0.3 & 59.7 & 97 & 87 \\
\hline 6 & 319 & 19.0 & 46.0 & 11.0 & 0 & 7.7 & 37.5 & 3.8 & 41.3 & 90 & 58 \\
\hline Mean & 312.3 & 22.3 & 45.0 & 5.9 & 0.4 & 3.4 & 46.6 & 5.5 & 52.1 & 92.8 & 71.2 \\
\hline$\pm \mathrm{SD}$ & \pm 63.6 & \pm 9.3 & \pm 13.8 & \pm 6.9 & \pm 0.9 & \pm 2.9 & \pm 11.0 & \pm 5.2 & \pm 13.8 & \pm 3.1 & \pm 11.3 \\
\hline
\end{tabular}

TST: total sleep time; REM: rapid eye movement; $\mathrm{AHI}$ : apnoea/hypopnoea index; $\mathrm{Sa}_{\mathrm{a}} \mathrm{O}_{2}$ : arterial oxygen saturation. (1 mmHg=0.133 kPa.)

systolic BP were $162.4 \pm 32.6 \mathrm{mmHg}$ at the beginning of apnoea and $177.0 \pm 35.6 \mathrm{mmHg}$ at the end $\left(\Delta B P_{\text {sys }}\right.$ $14.7 \pm 20.1 \mathrm{mmHg} ; \mathrm{p}<0.0001)$. The corresponding $P_{\text {oes }}$ were $-4.1 \pm 5.1 \mathrm{mmHg}$ at the beginning of apnoea and $-19.9 \pm 10.0 \mathrm{mmHg}$ at the end $\left(\Delta P_{\text {oes }} 15.8 \pm 9.9 \mathrm{mmHg}\right.$; $\mathrm{p}<0.0001)$. $S \mathrm{a}, \mathrm{O}_{2}$ was $96.2 \pm 2.1 \%$ at the beginning of apnoea and $88.5 \pm 5.1 \%$ at the end $\left(\Delta \mathrm{Sa}_{\mathrm{a}} \mathrm{O}_{2} \quad 7.7 \pm 4.9 \%\right.$; $\mathrm{p}<0.0001$ ). Analysis of the pulmonary haemodynamics of patient number 4 in detail revealed significant differences to the other patients. The mean $P$ pa,tm at the beginning of apnoea was $41.2 \pm 3.2$ versus $25.4 \pm 11.5 \mathrm{mmHg}(\mathrm{p}<0.0001)$ and the mean $P$ pa,tm at the end of apnoea was 54.0 \pm 7.2 versus $35.6 \pm 14.9 \mathrm{mmHg}(\mathrm{p}<0.0001)$. Moreover, the difference in $P$ pa,tm from the beginning to the end of apnoea was significantly higher in this patient in comparison with the other patients $(\Delta P \mathrm{pa}, \mathrm{tm}: 12.8 \pm 7.1$ versus $10.1 \pm 7.4$ $\mathrm{mmHg}, \mathrm{p}<0.05)$.

In order to test the possibility that repeated apnoeas could lead to a greater drop in $\mathrm{Sa}, \mathrm{O}_{2}$ with a progressive increase in $P$ pa,tm, we compared the first five apnoeas with the last five apnoeas of each 15 consecutive apnoeas of all patients and found no difference with regard to $P$ pa,tm, BP, $\mathrm{S}_{\mathrm{a}, \mathrm{O}_{2}}$ or $P$ oes.

With regard to the influence of apnoea duration, intrathoracic pressure swings and oxygen saturation on transmural pulmonary pressure we found the factors $\Delta S_{\mathrm{a}, \mathrm{O}_{2}}$ (odds ratio (OR) 1.45; $95 \%$ confidence interval (CI) 1.20$1.76 ; \mathrm{p}<0.0001)$ and $\triangle P_{\text {oes }}(\mathrm{OR} 1.22 ; 95 \%$ CI $1.11-1.34$; $\mathrm{p}<0.0001)$ were independently associated with $\Delta P$ pa,tm in a multiple regression analysis. Apnoea duration and $\triangle \mathrm{BP}-$ sys were not associated.

Analysis of the NREM apnoeas during the night revealed that the apnoea duration was significantly longer $(\mathrm{p}<0.05)$ at the middle of the sleep study $(30.1 \pm 16.8 \mathrm{~s})$ than at the beginning $(17.9 \pm 6.4 \mathrm{~s})$ or the end $(20.2 \pm 9.0 \mathrm{~s})$. In addition, $\Delta \mathrm{Sa}_{2} \mathrm{O}_{2}, \Delta P_{\text {oes}}$, and $\Delta P$ pa,tm were all significantly higher $(\mathrm{p}<0.05)$ in the apnoeas in the middle of the sleep study than at the beginning or the end (fig. 3a-d). $\triangle \mathrm{BP}_{\text {sys }}$ was highest in the middle of the sleep study as well, but this difference was not statistically significant (fig. 3e). The absolute values toward the end of the apnoeas had the highest systolic $P$ pa,tm at the middle of the sleep study $(40.6 \pm 15.9 \mathrm{mmHg})$ in comparison to the beginning $(38.5 \pm 14.8 \mathrm{mmHg})$ and the end $(36.7 \pm 15.7 \mathrm{mmHg})$, but this difference was not statistically significant. Systolic BP at apnoea end was slightly, but not significantly higher at the middle of the sleep study $(179.7 \pm 35.7$ $\mathrm{mmHg})$ than at the beginning $(177.9 \pm 36.2 \mathrm{mmHg})$ or the end $(173.4 \pm 34.7 \mathrm{mmHg})$. The corresponding $P$ oes values toward the end of the apnoeas were significantly lower ( $\mathrm{p}<$ $0.05)$ in the middle of the sleep study $(-23.4 \pm 10.2 \mathrm{mmHg})$ than at the beginning $(18.0 \pm 9.1 \mathrm{mmHg})$ or the end $(-18.3 \pm$ $9.9 \mathrm{mmHg}$ ).

The values of $\mathrm{Sa}_{\mathrm{a}} \mathrm{O}_{2}$ at the end of the apnoeas were also significantly lower $(\mathrm{p}<0.05)$ in the middle of the sleep study $(85.7 \pm 5.6 \%)$ than at the beginning $(90.1 \pm 4.2 \%)$ or the end $(89.7 \pm 4.1 \%)$.

\section{Discussion}

We found that the difference in the Poes as an estimate of intrathoracic pressure swings within an apnoea and the difference in $\mathrm{Sa}_{\mathrm{a}} \mathrm{O}_{2}$ during an apnoea were independently associated with an increase in $P$ pa,tm from the beginning to the end of an apnoea. Analysis of these differences in $P$ pa,tm, BP, $P_{\text {oes }}$ and $S \mathrm{a}_{2} \mathrm{O}_{2}$ with regard to the time course of a whole sleep study revealed that the greatest differences and the highest absolute values were found in the middle of the sleep study. In addition, apnoea had the longest duration in the middle of the sleep study.

In order to investigate the pulmonary haemodynamic characteristics throughout an obstructive apnoea cycle, the best way is to analyse $P_{\mathrm{pa}, \mathrm{tm}}$, i.e. intravascular $P_{\mathrm{pa}}$ minus intrathoracic pressure, as first described systematically by MarRoNe et al. [6]. They found that the apparent and irregular decline in intravascular values during apnoea, followed by a sudden rise at resumption of breathing, was replaced by a regular increase in transmural pressure up to a maximum value during the final occluded efforts and sustained during the early phase of hyperventilation. Our results were similar to these findings with a progressive increase in systolic $P$ pa,tm of $10 \mathrm{mmHg}$ as a mean towards the end of apnoea. Among the underlying mechanisms it was suggested that alveolar hypoxia played an important role, because a significant negative correlation between $P$ pa,tm and $\mathrm{Sa}, \mathrm{O}_{2}$ was found in most patients [6]. This hypothesis was further tested by evaluating the effect of oxygen administration on $P$ pa,tm during obstructive ap-noeas [10]. However, in most patients, oxygen administration affected neither mean $P$ pa,tm, nor the amplitude of $P$ pa,tm swings [10]. On the other hand, oxygen administration prevented the occurrence of pulmonary hypertensive peaks in a dog model of obstructive sleep apnoea [9]. Re-cently, LaKs et al. [21] examined the awake $P$ pa response to a ramp of acute hypoxia similar to that found in sleep apnoea and the interaction between hypoxia and hypercapnia. They found a $P$ pa increase in both normal subjects and patients with obstructive sleep apnoea exposed to a ramp of acute 

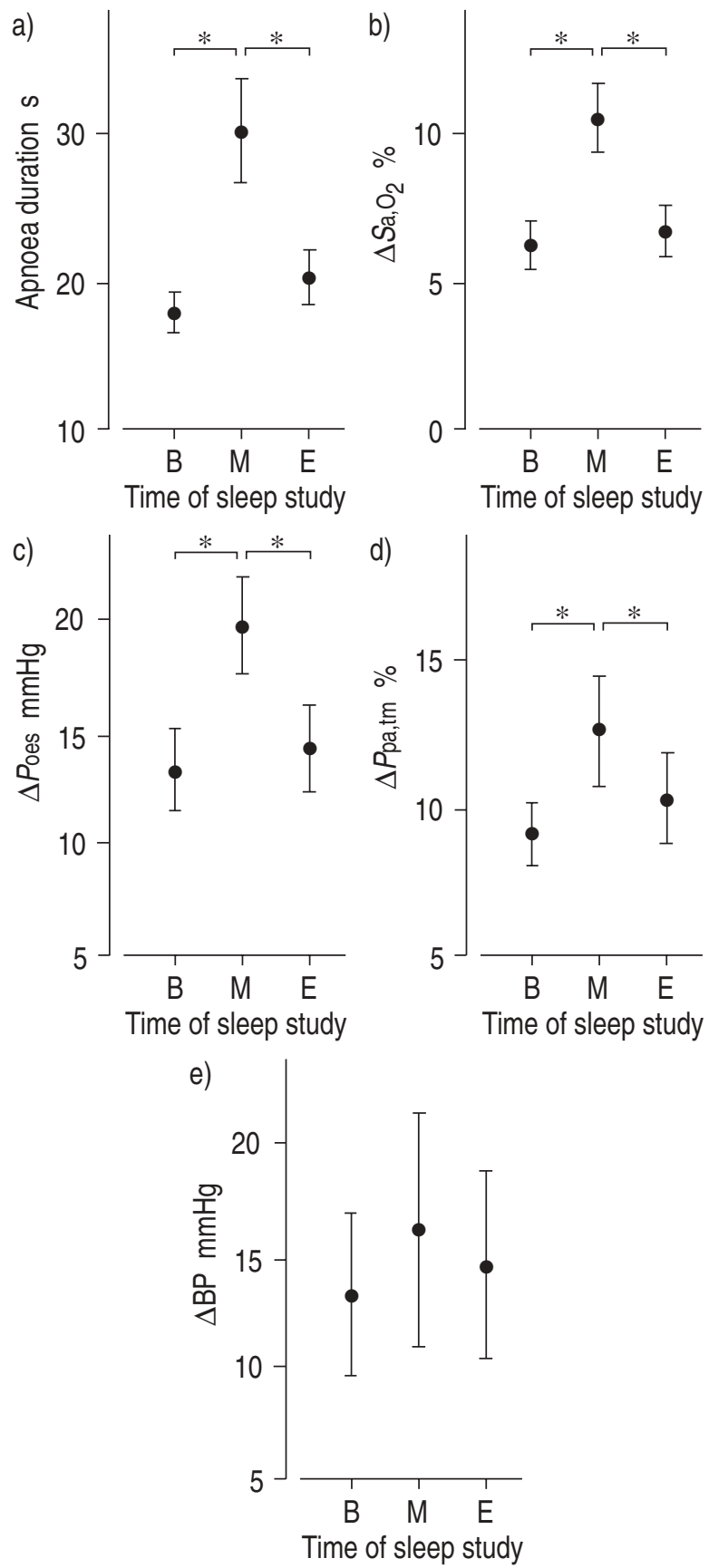

Fig. 3. - Comparison of: a) apnoea duration; b) changes in arteria oxygen saturation $\left.\left(\Delta \mathrm{S}_{\mathrm{a}, \mathrm{O}_{2}}\right) ; \mathrm{c}\right)$ changes in oesophageal pressure $(\Delta P$ oes $) ; \mathrm{d})$ changes in transmural pulmonary artery pressure $(\Delta P \mathrm{pa}, \mathrm{tm})$; and e) changes in blood pressure $(\triangle \mathrm{BP})$ at the beginning $(\mathrm{B})$, middle $(\mathrm{M})$, and end (E) of study. Data presented as means $\pm 95 \%$ confidence interval. *: $\mathrm{p}<0.05(1 \mathrm{mmHg}=0.133 \mathrm{kPa})$.

isocapnic hypoxia, but there were clear interindividual differences in $P$ pa response. Hypercapnia did not produce clinically significant changes in $P$ pa in either group.

In addition to the effects of hypoxaemia on the pulmonary haemodynamics, mechanical factors, especially intrathoracic pressure swings, have to be considered, as first suggested by PoDszus et al. [15]. Unfortunately, they did not record intrathoracic pressures in order to calculate $P$ pa,tm. Our data strongly support the fact that both oxygen desaturation and intrathoracic pressure swings account for the changes in $P$ pa,tm within an apnoea. This is consistent with the data from MARRONE et al. [11], who observed rapid changes which reflect intrathoracic pressure variations and slower changes likely to be caused by $\mathrm{Sa}_{\mathrm{a}} \mathrm{O}_{2}$ chan-ges. In contrast to our study, they investigated firstly $P$ pa,tm beat-by-beat, in reference to the immediately preceding end-diastole $P_{\mathrm{oes}}$ and, secondly, $P$ pa,tm changes in reference to $S_{\mathrm{a}, \mathrm{O}_{2}}$ changes within an apnoea. We analysed the changes in $S_{\mathrm{a}, \mathrm{O}_{2}}$ and $P_{\mathrm{oes}}$ as compared to $P$ pa,tm from the beginning to the end of the apnoea in one model, because $P$ oes as well as $S_{\mathrm{a}, \mathrm{O}_{2}}$ decrease progressively towards the end of an obstructive apnoea. Consequently, both factors should be investigated together in one model. In addition, we analysed arterial BP as a rough estimate of left ventricular afterload. We did not include the absolute values at the end of the apnoea in this model but the changes from the beginning to the end which may better reflect the dynamic process of intrathoracic pressure swings.

The patient (number 4 ) with markedly elevated $P$ pa at rest and during exercise had more pronounced changes in $P$ pa,tm during apnoeas than the other patients. The repetitive elevations in $P$ pa,tm during apnoeas may be crucial for the development of elevated $P$ pa awake in this patient.

Prolonged oxygen desaturation may lead to hypoxic vasoconstriction and therefore result in an increase in $P$ pa,tm, but intrathoracic pressure swings may also affect the pulmonary circulation since it has been demonstrated that $P$ pa,tm rises during snoring, independent of changes in $S_{\mathrm{a}, \mathrm{O}_{2}}$ [16]. An increase in $P$ pa,tm could be a direct consequence of right ventricular afterload and output due to an increase in blood volume from prolonged negative intrathoracic pressure. The effects of low intrathoracic pressure on the left heart could be another mechanism. Reduced intrathoracic pressure can increase left ventricular afterload as shown by elevated left ventricular volumes due to Mueller manoeuvres [17, 18], and this may explain the development of pulmonary oedema in obstructive sleep apnoea [19]. The effects on left ventricular afterload are still under debate. We found no association of systolic BP changes as a rough estimate of left ventricular afterload with the changes in $P$ pa,tm in our study. However, it is difficult to investigate the contribution of the mechanical factors in detail in such a clinical study. This could be aimed with an experimental setting of an animal study. Moreover, other factors such as the role of the sympathetic response or reflex mechanisms have to be considered [20]. In fact, we analysed all apnoeas in NREMsleep. The effect in rapid eye movement (REM)-sleep is not known, since in REM-sleep apnoeas may be longer and the extent of $S \mathrm{a}, \mathrm{O}_{2}$ reduction pronounced. In addition, the influence of reflex mechanisms and the sympathetic tone may be different in REM-sleep.

We examined a possible progressive increase in $P$ pa during the night, as had been pointed out in early studies [22], by dividing the sleep study in three phases of two hours, beginning, middle and end. We found no progressive increase throughout the night, but found the highest values and marked changes from apnoea beginning to apnoea end in the middle of the sleep study. The fact that apnoea duration was the longest and $\mathrm{Sa}_{\mathrm{a}} \mathrm{O}_{2}$ and $P$ oes were the lowest in this period suggests that these factors played a major role. Recently, SFORZA et al. [23] found a nocturnal trend of a small progressive increase of $P$ pa in patients with obstructive sleep apnoea, but not in snorers, by analysing 
selected apnoeas every hour of the sleep study. They concluded that this increase in $P$ pa reflects the cumulative effects of apnoeas and nocturnal hypoxaemia. However, apnoea duration increased throughout the night in their study as well and the effect of intrathoracic pressure is not known, since $P_{\text {oes }}$ was not recorded.

In conclusion, transmural pulmonary artery pressure increases from the beginning towards the end of apnoea. A drop in arterial oxygen saturation and mechanical factors as an increase in negative thoracic pressure are independently associated with this rise in transmural pulmonary artery pressure. There is no progressive increase of transmural pulmonary artery pressure throughout the night.

Acknowledgements: The authors wish to thank T. Podszus for helpful discussion.

\section{References}

1. Kessler R, Chaouat A, Weitzenblum E, et al. Pulmonary hypertension in the obstructive sleep apnoea syndrome: prevalence, cause and therapeutic consequences. Eur Respir J 1996; 9: 787-794.

2. Chaouat A, Weitzenblum E, Krieger J, Oswald M, Kessler R. Pulmonary hemodynamics in the obstructive sleep apnoea syndrome. Results in 220 consecutive patients. Chest 1996; 109: 380-386.

3. Laks IL, Lehrhaft B, Grunstein RR, Sullivan CE. Pulmonary hypertension in obstructive sleep apnoea. Eur Respir $J$ 1995; 8: 537-541.

4. Schroeder JS, Motta J, Guilleminault C. Hemodynamic studies in sleep apnoea. In: Guilleminault C, Dement WC, eds. Sleep Apnoea Syndromes. New York, Alan Liss, 1978: pp. 177-196.

5. Coccagna G, Mantovani M, Brignani F, Parchi C, Lugaresi E. Continuous recording of the pulmonary and systemic arterial pressure during sleep in syndromes of hypersomnia with periodic breathing. Bull Physiopathol Respir 1972; 8: $1159-1172$.

6. Marrone O, Bellia V, Ferrara G, et al. Transmural pressure measurements. Importance in the assessment of pulmonary hypertension in obstructive sleep apnoeas. Chest 1989; 95: 338-342.

7. Podszus T, Greenberg H, Scharf SM. Influence of sleep state and sleep-disordered breathing on cardiovascular function. In: Saunders NA, Sullivan CE, eds. Sleep and Breathing. New York, Marcel Dekker, 1994: pp. 257-310.

8. Bradley T. Right and left ventricular function impairment and sleep apnoea. Clin Chest Med 1992; 13: 459-479.
9. Iwase N, Kikuchi Y, Hida W. Effects of repetitive airway obstruction on $\mathrm{O}_{2}$ saturation and systemic and pulmonary artery pressure in anesthetized dogs. Am Rev Respir Dis 1992; 145: 1402-1410.

10. Marrone O, Bellia V, Pieri D, Salvaggio A, Bonsignore G. Acute effects of oxygen administration on transmural pul-monary pressure in obstructive sleep apnoea. Chest 1992; 101: 1023-1027.

11. Marrone O, Bonsignore MR, Romano S, Bonsignore G. Slow and fast changes in transmural pulmonary artery pressure in obstructive sleep apnoea. Eur Respir J 1994; 7: 2192-2198.

12. Baydur A, Behrakis PK, Zin WA, Jaeger M, Milic-Emili J. A simple method for assessing the validity of the esophageal balloon technique. Am Rev Respir Dis 1982; 128: 788-791.

13. Rechtschaffen A, Kales A. A Manual of Standardized Terminology, Techniques and Scoring System for Sleep Stages in Human Subjects. Washington DC, National Institutes of Health, 1986; Publication No. 204.

14. Guilleminault C, Tilkian A, Dement WC. The sleep apnoea syndromes. Annu Rev Med 1976; 27: 465-484.

15. Podszus T, Mayer J, Penzel T, Peter JH, von Wichert P. Nocturnal hemodynamics in patients with sleep apnoea. Eur J Respir Dis 1986; 69: Suppl. 146, 435-442.

16. Podszus T, Peter JH, Ploch T, Schneider H, von Wichert P. Pulmonalarterieller Blutdruck und Schnarchen. Prax Klin Pneumol 1991; 45: 233-238.

17. Buda AJ, Pinsky MR, Ingels NB, Daughters GIL, Stinson EB, Alderman EL. Effect of intrathoracic pressure on left ventricular performance. N Engl J Med 1979; 30: 453-459.

18. Scharf SM, Brown R, Tow DE, Parisi AF. Cardiac effects of increased lung volume and decreased pleural pressure. J Appl Physiol 1979; 47: 257-262.

19. Chaudhary BA, Ferguson DS, Speir WA. Pulmonary edema as a presenting feature of sleep apnoea syndrome. Chest 1982; 82: 122-124.

20. Naeije R, Lejeune P, Leeman M, Melot C, Closset J. Pulmonary vascular responses to surgical chemodenervation and chemical sympathectomy in dogs. J Appl Physiol 1989; 66: 42-50.

21. Laks L, Lehrhaft B, Grunstein RR, Sullivan CE. Pulmonary artery pressure response to hypoxia in sleep apnoea. Am J Respir Crit Care Med 1997; 155: 193-198.

22. Lonsdorfer J, Meunier-Carus J, Lampert-Benignus E, et al. Hemodynamic and respiratory aspects of the Pickwickian syndrome. Bull Physiopathol Respir 1972; 8: 1181-1192.

23. Sforza E, Laks L, Grunstein RR, Krieger J, Sullivan CE. Time course of pulmonary artery pressure during sleep in sleep apnoea syndrome: role of recurrent apnoeas. Eur Respir J 1998; 11: 440-446. 